diagrams. The results, in this area, confirm the general simplicity of the regime and do not therefore add greatly to the information obtained by using mean monthly rainfall values, but a clear demonstration is afforded of the value of a logarithmic scale in plotting seasonal variation. Variability of monthly precipitation increases markedly $(a)$ from north to south and $(b)$ from lower to higher elevations.

Mr. E. G. Bowen showed the results of attempting to map the 'spheres of influence' of the missionary saints of the Dark Ages, choosing St. Samson and St. Columba, in Celtic Britain. These spheres seem to coincide with cultural provinces determined on the basis of archæological distributions, but in the discussion various reasons were suggested for this. Mr. K. H. Huggins's paper on "Types of Settlement in the Scottish Highlands" was concerned to a considerable degree with the delimitation of the 'Highlands' as distinct from the 'Lowlands'. By using such criteria as structure, elevation, 'amount of relief', proportion of moorland, type and density of settlement, different 'limits' to the Highlands are obtained, and there is clearly a central area where all the Highland characteristics are present, fringed by a broad transitional area.

Mr. K. C. Edwards dealt with the consequences of recent improvements in the River Trent as a waterway--including the growth of Nottingham as a leading distribution centre for petroleum products.

The distribution of settlements, permanent and temporary, and of cultivated crops in Alpine valleys, is a subject of considerable importance and concerning which there is an extensive literature. But an important advance in knowledge is marked by Miss Alice Garnett's careful and suggestive study of insolation. A formula for the calculation of insolation intensity at any given spot (based on slope, aspect and the sun's elevation) has been devised and it is possible to construct 'intensity maps'. Special importance is attached to spring noonday intensity values. At the same time 'time periods of insolation' are mapped and the results are combined.
This method of investigation seems to demonstrate a possible law of alpine settlements, namely, that above c. 1,100 m., all permanent settlements avoid the areas of winter shade, while ubac villages follow the edge of the winter noonday shadow line. For regions studied in lat. $46^{\circ} \mathrm{N}$., above $1,400 \mathrm{~m}$., wheat, barley and rye require at least an $80-90$ per cent spring noonday intensity. Wheat can ripen up to c. $1,600 \mathrm{~m}$. where a noonday equinox intensity exceeds 90-95 per cent of the maximum possible at that time, provided these areas also have long time periods of insolation. Areas with a 50-70 per cent intensity are generally given over to meadow, while land with an intensity value of less than 50 per cent is left to forest. It is abundantly clear that this study has an important bearing on land planning in alpine areas and is capable of extension to regions of lower relief in higher latitudes-for example, to the Highland valleys of Scotland and Antrim, where the intensity and time period of insolation would seem to have a bearing on health problems.

Dr. S. W. Wooldridge, by a preliminary analysis of areas in the London basin, dealt with the 'facet' as the ultimate unit of geographical analysis. The facet is difficult of definition though the concept is clear. A river terrace, a dip slope, a plateau (even if only a fragment) are 'facets' which thus correspond in general with geomorphological units, but in detail have different boundaries. Thus the 'Taplow Terrace facet' as a geographical unit does not coincide with the distribution of the Taplow Terrace gravels of the geological map.

The last session of the meeting was devoted to a discussion of Prof. C. B. Fawcett's paper on the relations between the advance of science in geography and the life of the community, read before the British Association at Aberdeen in September last.

The Institute, in accordance with its avowed policy of publishing memoirs too long for inclusion in existing periodicals but unsuitable for publication in book form, has issued, as its first volume, Dr. R. O. Buchanan's study of the pastoral industries of New Zealand.

L. Dudley Stamp.

\section{Annual Meeting of the}

$\mathrm{T}$ HE annual meeting of the Mathematical Association was held at the Institute of Education, London, W.C.1, on January 7-8, under the presidency of Prof. E. H. Neville, of the University of Reading. The following distinguished mathematicians were elected honorary members of the Association: Profs. E. Borel (Paris), J. Hadamard (Paris), G. H. Hardy (Cambridge), D. E. Smith (New York), E. T. Whittaker (Edinburgh). Mr. A. W. Siddons, of Harrow School, was elected president of the Association for the fortheoming year.

In his presidential address, entitled "The Food of the Gods", Prof. Neville dealt with a problem in mathematical education which is of considerable importance and difficulty. From the fact that the preparation given to a schoolboy a quarter of a century ago for an entrance scholarship examination at Cambridge would be adequate to this examination as it is at present, while the undergraduate of those days would find many of the questions in a modern tripos incomprehensible, he deduced that the universities of to-day build a different mathematical structure, but are content to build it on foundations which have not changed since the beginning of the

\section{Mathematical Association}

century. Since this difference is due to the direct influence of changes in emphasis in creative mathematics on the teaching at the universities, he urged that such changes ought to have a greater and far more rapid influence on teaching at the schools than they seem to have. Room for new ideas can only be found by omissions or condensations, by the expulsion from the curriculum of methods and ideas once valuable but now outworn, kept in place through inertia. To demonstrate the possibility of such a reform, Prof. Neville gave some examples illustrating the successful working of a similar process at the undergraduate stage. To bring this about at the school stage, the young teacher has the knowledge of what is important, the old teacher has the experience of what is practicable and the influence to effect the changes he desires, and Prof. Neville sees in this an opportunity for the generations to co-operate. At present, each advance is followed by a score of years in which the backward schools and the popular textbooks creep up to the leaders ; he envisages a responsiveness everywhere to the ferment of current ideas, which should re. sult in a mathematical nourishment requiring no long periods of accommodation, the true 'food of the gods'. 
Following the presidential address, Brigadier H. St. J. L. Winterbotham, Director-General of Ordnance Survey, spoke on "Geography and Mathematics", detailing the many and various ways in which a knowledge of mathematics assists geographical progress.

of the four papers which occupied the morning of January 8 , that which attracted most attention was given by Mr. G. L. Parsons, of Merchant Taylors' School, under the title "The Work of a Junior Mathematical Association". The members of this Association are some eight public schools in the London area ; five meetings are held each year, and a good attendance of the mathematically-minded. pupils in the higher forms of these schools is obtained. Occasionally the meetings are addressed by distinguished adult mathematicians, but more frequently by the boys themselves, who are thus encouraged in habits of independent thought and research. Sir James Jeans is the president of the Association, and the president's annual essay prize attracts many excellent entries.
In the afternoon, Prof. D, R. Hartree, of the University of Manchester, gave a paper on "The Bearing of Statistical and Quantum Mechanics on School Work" ; after asserting that the new mechanics has no direct bearing on school work, he explained in elementary terms some of the basic concepts of the subject in such a way as to illustrate the indirect influence the new ideas might be expected to exert on school work in mathematical physies. Following this, the warm interest which members of the Association invariably take in points of teaching practice was again demonstrated by a lively discussion on "The First Encounter with a Limit", in which teachers from the schools and universities took part. The meeting ended with a delightful lecture by Prof. G. H. Hardy on "The Theorem of the Arithmetic and Geometric Means", in the course of which he discussed several different proofs of the fundamental inequality connecting these two means, and incidentally directed attention to some very important, but much neglected, work by Dr. R. F. Muirhead on inequalities of a more general type.

\section{Work of the Rothamsted Experimental Station}

$\mathrm{A}^{\mathrm{s}}$ knowledge of plant growth accumulates, the number of points from which the problem of crop production can be attacked increases. Since the foundation of the Rothamsted Experimental Station in 1843, the activities of the Station have been steadily extended so as to make it possible to follow up some of the new problems which are continually brought to light by the work there and elsewhere. The study of quality in crops, for example, has led to a considerable amount of work in conjunction with the Institute of Brewing, the Millers' Research Association, sugar beet factories, etc. The work on malting barley, for example, has outgrown the accommodation at Rothamsted, and, having reached the stage where closer contact with the brewing industry was necessary, has been transferred elsewhere.

The Rothamsted report for $1933^{*}$ gives a brief summary of the various problems under investigation during the year at Rothamsted and Woburn, and also includes trials carried out at outside centres. Though the field and laboratory work are really one, they are, for the sake of convenience, dealt with separately in the report. The report includes results of some schemes of experiments conducted on a uniform basis at a number of centres; for example, results of ten years experiments with malting barley, and of experiments on the effect of fertilisers on the yield and quality of sugar beet. A list of papers published from the Station is also included, together with comments on the contents of each.

The problem of soil organic matter continues to receive attention, the plan of investigation being one designed and begun some years ago. This problem is important in view of the possibilities of mechanised cereal growing, and the Rothamsted experiment will help in answering the question which will inevitably be asked by those contemplating farming under the new conditions-how far it is possible to practise mechanised corn-growing and pay no attention to replenishing the stocks of soil organic matter by the addition of farmyard manure, sheep folding, etc. * Rothamsted Experimental Station, Harpenden: Lawes Agri-
cultural Trust. Report for 1933. Pp. 200. (Harpenden : Rothamsted cultural Trust. Report for 1933. Pp. 200.
Experimental Station, 1934.) $2 s$. $6 \dot{d}$.
That the solution of this problem is not so simple as was once considered is gathered from the observation in the report that green manures do not keep up the productiveness for wheat of the light soil at Woburn, and that the residual values of farmyard manure and of cake and corn fed to animals at Woburn appeared to be much less than is indicated by the recognised tables. The latter observation has also an important bearing on the existing method of assessing certain compensations due on the termination of tenancies.

Dr. R. A. Fisher, who left in October 1933 to take up his new duties as Galton professor in the University of London, has written a short account of the contribution of Rothamsted to the development of the science of statistics. One development, namely, the realisation that it was necessary to treat the question of field procedure and that of statistical analysis as but two aspects of a single problem, has resulted in definitely increasing the value of experimental work. To quote Dr. Fisher, "By applying statistical methods not only to the interpretation but also to the design of experiments, it is not uncommon for the value of the experiment to be increased five or ten fold, a result which could not be obtained from improved methods of interpretation only". It is doubtful, for example, if the capacity of superphos. phate and sulphate of ammonia for reinforcing each other's effect could have been detected and estimated if it were not for the improvements in plot technique and interpretation of results. The Statistical Laboratory has tackled the problem of technique in livestock trials, having commenced by a successful pig feeding experiment; the pens and feeding arrangements have been designed so that all types of rations are distributed equally over all the groups of pens instead of all the pigs on one treatment being in the same pen.

The report is essential for those engaged in teaching or research work. The long-term experiments and the thoroughness of the liaison between field and laboratory work give added value to the work at Rothamsted. The practical farmer will also find the report interesting, but most of the results will doubtless reach him through the medium of the agricultural Press. 